\title{
Elastic behavior of a slender air tube combined with wires inspired by elongation of plant stem
}

\author{
Takara Muto*, Ken'ich Kawaguchi ${ }^{\dagger}$ \\ ${ }^{*}$ School of Engineering, The University of Tokyo \\ 7-3-1 Hongo, Bunkyo-ku, Tokyo, 113-0033, Japan \\ E-mail: t-muto@iis.u-tokyo.ac.jp \\ ${ }^{\dagger}$ Institute of Industrial Science(IIS), The University of Tokyo \\ 4-6-1 Komaba, Meguro-ku, Tokyo 153-8505, Japan \\ Email: kawaken@iis.u-tokyo.ac.jp, Web page: http://space.iis.u-tokyo.ac.jp/
}

\begin{abstract}
Air tube is excellent in lightness as an element to transfer axial force, though is soft compared to other elements. To enhance stiffness, it is thought of effective to introduce tension to wires by air pressure, and the method is like cell membrane and cell wall in elongation of plant cell.[1]

This paper report about experimental studies of behavior of a slender air tube combined with stainless wires. In this structure air tube and wires are fixed at the ends, and tension is introduced by enhancing internal air pressure. We prepared 3 specimens and their radius, heights and weights are $400 \mathrm{~mm}, 800 \mathrm{~mm}$ and $0.7-1.2 \mathrm{~kg}$ for each.

The result shows that elasticity of the specimens in the range from $52 \mathrm{~N} / \mathrm{mm}$ to $107 \mathrm{~N} / \mathrm{mm}$ and we realized getting them stiffer than air tube without wires. In addition, the structure was able to deploy stably and get $15 \mathrm{~mm}$ longer by relaxing wires using turnbuckle.

The structure has the potential to be applied to working platform which can stably move up and down by supplying air from the ground as plant stem grow up and stand much higher by absorbing water.
\end{abstract}

\section{REFERENCES}

[1] Ryoichi Yamamoto (2003) "Kuki no seicho to ouryokukannwa", Japan Biorheology Academic Conference vol.17:29-35 